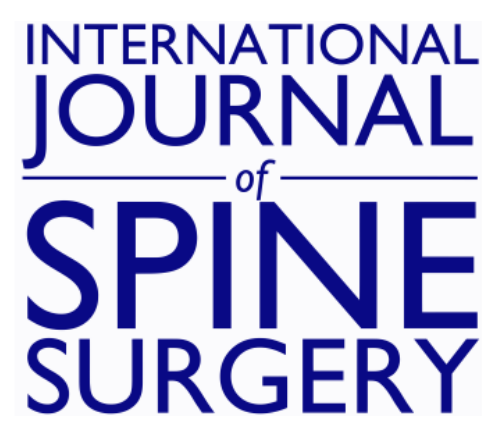

\title{
Does Clinical Photography Influence Satisfaction With Surgery in Adult Patients Operated on for Spinal Deformity?
}

\author{
ALEJANDRO GOMEZ-RICE, CRISTINA MADRID, ENRIQUE IZQUIERDO, FERNANDO \\ MARCO-MARTÍNEZ, JESÚS A.F. TRESGUERRES and FELISA SANCHEZ-MARISCAL
}

Int J Spine Surg 2021, 14 (6) 1037-1042

doi: https://doi.org/10.14444/7155

http://ijssurgery.com/content/14/6/1037

This information is current as of April 26, 2023.

Email Alerts Receive free email-alerts when new articles cite this article. Sign up at: http://ijssurgery.com/alerts 


\title{
Does Clinical Photography Influence Satisfaction With Surgery in Adult Patients Operated on for Spinal Deformity?
}

\author{
ALEJANDRO GOMEZ-RICE,,${ }^{1,2}$ CRISTINA MADRID, ${ }^{3}$ ENRIQUE IZQUIERDO,${ }^{3}$ FERNANDO MARCO- \\ MARTÍNEZ, ${ }^{2,4,5}$ JESÚS A.F. TRESGUERRES, ${ }^{6}$ FELISA SANCHEZ-MARISCAL ${ }^{7}$ \\ ${ }^{1}$ Hospital UniversitarioRamon y Cajal, Madrid, Spain, ${ }^{2}$ Complutense University of Madrid, Madrid, Spain, ${ }^{3}$ Hospital Universitario de Getafe, ${ }^{4}$ Hospital Clinico \\ San Carlos, Madrid, Spain, ${ }^{5}$ Department of Surgery, School of Medicine, Complutense University of Madrid, Madrid, Spain, ${ }^{6}$ Department of Physiology, School \\ of Medicine, Complutense University of Madrid, Madrid, Spain, ${ }^{7}$ Hospital Universitario Rey Juan Carlos, Madrid, Spain
}

\begin{abstract}
Background: Recently published data suggest that showing patients operated on for adolescent idiopathic scoliosis or kyphosis their preoperative and postoperative photographs may enhance their satisfaction and self-image as measured by Scoliosis Research Society Health-Related Quality of Life Questionnaire (SRS-22) scores. No data exist for adult spinal deformity (ASD) surgery. The aim of this study is to determine the effect on patient postoperative satisfaction and self-image of showing adult deformity patients their preoperative and postoperative whole body photographs.

Methods: This was a nonconcurrent prospective study. Patients operated on for ASD with a minimum 2-year postoperative follow-up who had preoperative full-body photographs taken by a professional photographer were included. Two follow-up visits were arranged 7 days apart. In the first visit, patients completed the SRS-22 questionnaire, and full-body standing photographs were taken. In the second visit, patients were asked to complete again questions 4, 6, 10, 14, 19 (self-image), 21, and 22 (satisfaction) of the SRS-22 after seeing their preoperative and postoperative full-body photographs.

Results: Thirty patients (28 female) were included. The median age at surgery was 50 years (26-76). The median follow-up was 51 months (24-120). SRS-22 results at first visit were: activity $2.79 \pm 0.75$; self-image $2.71 \pm 0.82$; pain $2.53 \pm 1.10$; mental health $3.08 \pm 0.77$; satisfaction $3.46 \pm 1.20$; global $2.74 \pm 0.72$. SRS22 results at second visit were: self-image $2.9 \pm 0.75$; satisfaction $4.02 \pm 0.97$. After seeing the preoperative and final follow-up photographs, patients experienced an improvement in SRS-22 self-image $(P=.000)$ and satisfaction domains $(P=.011)$.

Conclusions: In patients operated on for ASD, showing preoperative and postoperative photographs improves patient satisfaction with surgery and self-image.

Level of Evidence: 3.

Clinical Relevance: Our results could be a starting point for introducing full-body clinical photographs as a routine clinical tool in adult deformity patients undergoing surgery.

Other \& Special Categories

Keywords: adult spinal deformity, quality of life, patient satisfaction, SRS-22, clinical photography
\end{abstract}

\section{BACKGROUND}

Delivering patient-centered care is an important component of a high-quality health care system. ${ }^{1}$ Patient satisfaction after spinal surgery is currently being used as a proxy for quality of care, caregiver performance, and process measures for hospitals. ${ }^{2,3}$ Bearing this in mind, identification of factors that may influence patient satisfaction is important.

Previously conducted studies have shown that adolescents operated for scoliosis ${ }^{4}$ and kyphosis ${ }^{5}$ improved their satisfaction as measured by Scoliosis Research Society Health-Related Quality of Life Questionnaire (SRS-22) scores after showing them preoperative and postoperative full-spine photographs. The influence of clinical photography in patient satisfaction after adult deformity surgery has not been previously reported.

Although it was designed for patients with adolescent idiopathic scoliosis, the SRS-22 is now widely used as an outcome instrument in patients with adult spinal deformity (ASD), ${ }^{2,6-8}$ and it has proven an excellent 7-day test-retest reliability. ${ }^{9}$

The SRS-22 self-image domain has proven to have a strong correlation with patient satisfaction for adult scoliosis surgery. ${ }^{2}$ The purpose of this study is to determine the effect on patient postoperative satisfaction and self-image of showing adult 


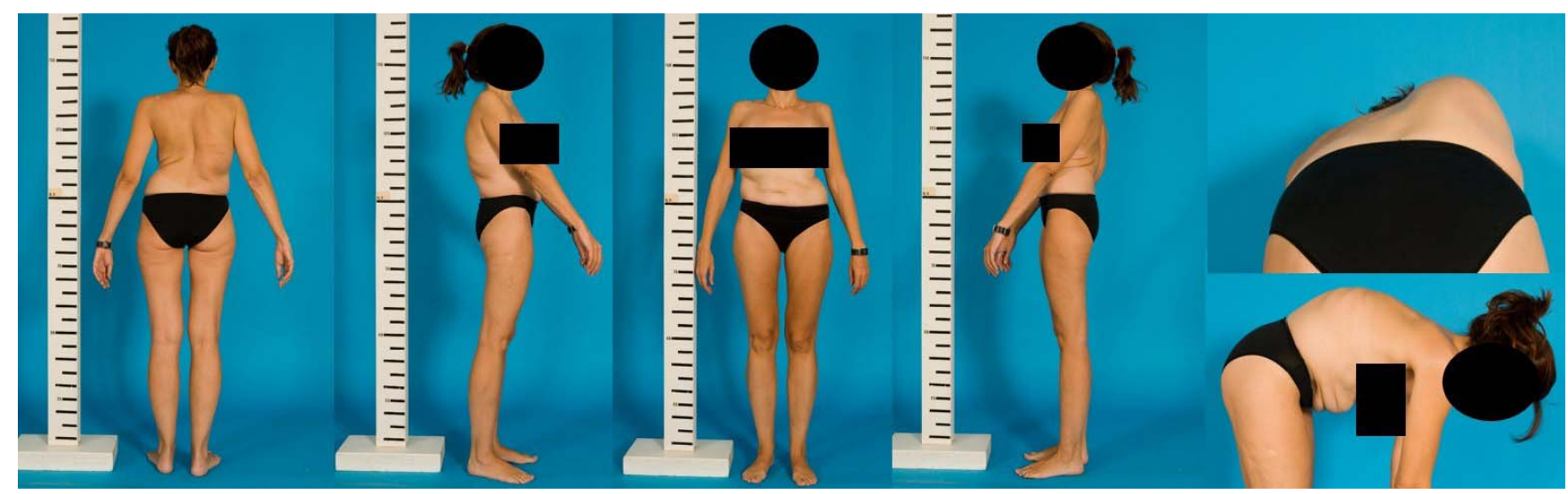

Figure 1. Preoperative photographs of an adult idiopathic scoliosis patient.

deformity patients their preoperative and postoperative whole-body photographs.

\section{METHODS}

\section{Study Design}

This is a single-center single-surgeon nonconcurrent prospective study approved by the Institutional Research Ethics Committee. Written informed consent was obtained from all patients after they were provided with a detailed information sheet. The null hypothesis is that satisfaction and selfimage in patients operated on for adult deformity are not affected by showing patients their preoperative and postoperative full-body photographs.

\section{Subject Inclusion}

Inclusion criteria were as follows: age at surgery older than 25 years, having professional clinical photographs taken before surgery, minimum 2-year follow-up after surgery, and having undergone 5 or more levels of fusion for idiopathic or degenerative scoliosis with main Cobb angle greater than $40^{\circ}$, sagittal and/or coronal imbalance greater than $5 \mathrm{~cm}$, T3-T12 kyphosis greater than $80^{\circ}$, and thoracolumbar kyphosis greater than $20^{\circ}$.

Exclusion criteria: tumors or neuromuscular, congenital, or traumatic deformity. Patients with a longer than 10-year follow-up were excluded in order to avoid that the natural aesthetic changes associated with aging could bias self-image assessment.

Out of 130 patients operated on for adult deformity between January 2007 and December 2016, 39 met our inclusion criteria. Two patients were deceased, 2 patients could not be contacted, and 4 patients lived far away and could not participate for logistic reasons. One patient refused to participate in our study. Thirty patients were finally included. Demographic data and patient's characteristics are summarized in Table 1.

\section{Data Collection}

Two outpatient visits were arranged 7 days apart. Data were collected by 2 researchers not involved in patient treatment. In the first visit, informed consent granting permission to use the photographs for this study was obtained from all individual participants included in the study. Subjects completed the SRS22 questionnaire, and full-body standing photographs were taken by a professional clinical photographer. All photographs-preoperative and postoperative - were taken by the same professional clinical photographer using similar camera settings and lighting in the same room and at the same distance.

Subjects were asked to stand relaxed during the photographic sessions. Photographs were taken from anterior, posterior, and lateral views in both the upright and the forward-bending positions (Figure 1).

In the second visit, patients were shown their preoperative and final follow-up photographs (Figure 2). After seeing the clinical photographs, they were asked again to answer questions 4, 6, 10, 14, 19 (self-image), 21, and 22 (satisfaction) of the SRS-22 questionnaire.

\section{Statistical Methods}

The collected data were analyzed using IBM SPSS Statistics 23 for Windows. Descriptive statistics are presented as mean, median, standard deviation, and range. A paired Wilcoxon test was 
Table 1. Patient characteristics.

\begin{tabular}{|c|c|c|c|c|c|}
\hline Patient & $\begin{array}{l}\text { Age at } \\
\text { Surgery, y }\end{array}$ & Sex & Diagnosis & Surgery & $\begin{array}{l}\text { Follow-Up, } \\
\text { mo }\end{array}$ \\
\hline 1 & 49 & Female & IS + Sag. Imb. & L2 PSO; multilevel SPO; T2-iliac fusion & 26 \\
\hline 2 & 51 & Female & $\begin{array}{l}\text { IS }+ \text { Sag. Imb. + PJK; previous Harrington } \\
\text { rod surgery }\end{array}$ & Multilevel SPO; T2-S1 fusion & 27 \\
\hline 3 & 29 & Female & IS & T2-L2 fusion & 27 \\
\hline 4 & 41 & Female & IS + Sag. Imb. & Multilevel SPO; T10-iliac fusion & 29 \\
\hline 5 & 66 & Female & $\mathrm{IS}+\mathrm{LSS}$ & T10-iliac fusion & 30 \\
\hline 6 & 62 & Female & IS + CCSI; previous Harrington rod surgery & L3 asymmetric PSO; T7-iliac fusion & 53 \\
\hline 7 & 68 & Female & $\mathrm{DS}+$ Cor. Imb. $+\mathrm{FB}$ & Multilevel SPO; T12-iliac fusion & 25 \\
\hline 8 & 62 & Female & $\mathrm{IS}+\mathrm{TLK}$ & T12 VCR; multilevel SPO T2-iliac fusion & 35 \\
\hline 9 & 63 & Female & $\mathrm{DS}+$ degenerative FB & Multilevel SPO; L2-iliac fusion & 49 \\
\hline 10 & 33 & Female & IS & T3-L4 fusion & 51 \\
\hline 11 & 33 & Female & IS & $\begin{array}{l}\text { Double approach; anterior T4-T9 discectomy; } \\
\text { multilevel SPO; T1-L3 fusion through a } \\
\text { posterior approach }\end{array}$ & 51 \\
\hline 12 & 73 & Female & $\mathrm{CCSI}+\mathrm{FB}$ & L4 PSO; T8-iliac fusion & 50 \\
\hline 13 & 70 & Female & Sag. Imb. + FB & L4 PSO; multilevel SPO; T4-iliac fusion & 43 \\
\hline 14 & 42 & Female & $\begin{array}{l}\text { IS }+ \text { Sag. Imb. }+ \text { LSS; previous Harrington } \\
\text { rod surgery }\end{array}$ & Multilevel PSO; T12-iliac fusion & 58 \\
\hline 15 & 57 & Female & $\begin{array}{l}\text { IS }+ \text { FB }+ \text { Sag. Imb.; previous double- } \\
\text { approach surgery }\end{array}$ & L4 PSO;T2-iliac fusion & 94 \\
\hline 16 & 61 & Female & Thoracic hyperkyphosis + Sag. Imb. & Multilevel SPO; C5-L4 fusion & 68 \\
\hline 17 & 70 & Male & Sag. Imb. + FB; previous lumbar fusion & L4 PSO; T10-iliac fusion & 24 \\
\hline 18 & 55 & Female & $\begin{array}{l}\text { Sag. Imb. }+ \text { FB + LSS; previous lumbar } \\
\text { fusion }\end{array}$ & L4 PSO; T8-iliac fusion & 45 \\
\hline 19 & 38 & Female & Thoracic hyperkyphosis & $\begin{array}{l}\text { Double approach; T7-T10 anterior discectomy } \\
\text { and fusion; C5-L3 fusion through a posterior } \\
\text { approach }\end{array}$ & 70 \\
\hline 20 & 41 & Female & IS & $\begin{array}{l}\text { Double approach; T10-L3 anterior discectomy } \\
\text { and fusion;T6-L5 fusion through a posterior } \\
\text { approach }\end{array}$ & 118 \\
\hline 21 & 48 & Female & Thoracic hyperkyphosis & Multilevel SPO; D2-L3 fusion & 120 \\
\hline 22 & 26 & Female & IS & Multilevel SPO; costoplasty; T2-L4 fusion & 119 \\
\hline 23 & 51 & Female & IS & $\begin{array}{l}\text { Double approach; D11-L4 anterior discectomy } \\
\text { and fusion; D10-L4 fusion through posterior } \\
\text { approach }\end{array}$ & 118 \\
\hline 24 & 48 & Male & Thoracic hyperkyphosis & Multilevel SPO; D2-L3 fusion & 42 \\
\hline 25 & 67 & Female & DS & Multilevel SPO; T10-L5 fusion & 87 \\
\hline 26 & 76 & Female & $\mathrm{FB}+$ Sag. Imb. & L4 PSO; T10-iliac fusion & 39 \\
\hline 27 & 44 & Female & $\mathrm{IS}+\mathrm{FB}$ & $\begin{array}{l}\text { Double approach; T10-L2 anterior discectomy } \\
\text { and fusion; T10-L5 fusion through posterior } \\
\text { approach }\end{array}$ & 93 \\
\hline 28 & 42 & Female & $\begin{array}{l}\text { IS }+ \text { FB }+ \text { Sag. Imb.; previous Harrington } \\
\text { rod surgery }\end{array}$ & L4 PSO; multilevel SPO; T4-S1 fusion & 92 \\
\hline 29 & 47 & Female & IS + Sag. Imb. & $\begin{array}{l}\text { Double approach; D11-L4 anterior discectomy } \\
\text { and fusion; T2-S1 fusion through posterior } \\
\text { approach }\end{array}$ & 120 \\
\hline 30 & 48 & Female & IS + CCSI; previous Harrington rod surgery & Multilevel SPO; T1-iliac fusion & 87 \\
\hline
\end{tabular}

Abbreviations: IS, idiopathic scoliosis; Sag. Imb., sagittal imbalance $>5 \mathrm{~cm}$; PJK, proximal junctional kyphosis; LSS, lumbar spinal stenosis; CCSI, combined coronal and sagittal imbalance; DS, degenerative scoliosis; Cor. Imb., coronal imbalance $>5 \mathrm{~cm}$; FB, flat back; TLK, thoracolumbar kyphosis; PSO, pedicle subtraction osteotomy; SPO, Smith-Petersen osteotomy; VCR, vertebral column resection.

performed to compare prephotography and postphotography SRS-22 results. A $P$ value of $<0.05$ was considered statistically significant.

\section{RESULTS}

Thirty patients were included in this study. Twenty-eight female and 2 male subjects were recruited. Median age at surgery was 50 years (range 26-76). Median postoperative follow-up was 51 months (range 24-120). The median number of fused levels was 13 (range 5-18). Six patients were treated by combined anterior and posterior ap- proach (double approach), while 24 patients were treated by a posterior-only approach.

Eighteen patients were operated on for idiopathic scoliosis, 3 for degenerative scoliosis with a coronal Cobb angle greater than $30^{\circ}$, and 4 patients for thoracic hyperkyphosis. Twelve patients presented with a sagittal imbalance greater than $5 \mathrm{~cm}, 1$ patient with a coronal imbalance greater than $5 \mathrm{~cm}$, and 3 patients with a combined sagittal and coronal imbalance (Table 1). Twenty-two patients underwent primary surgery, while 8 patients had been submitted to previous surgery. Five patients had a 


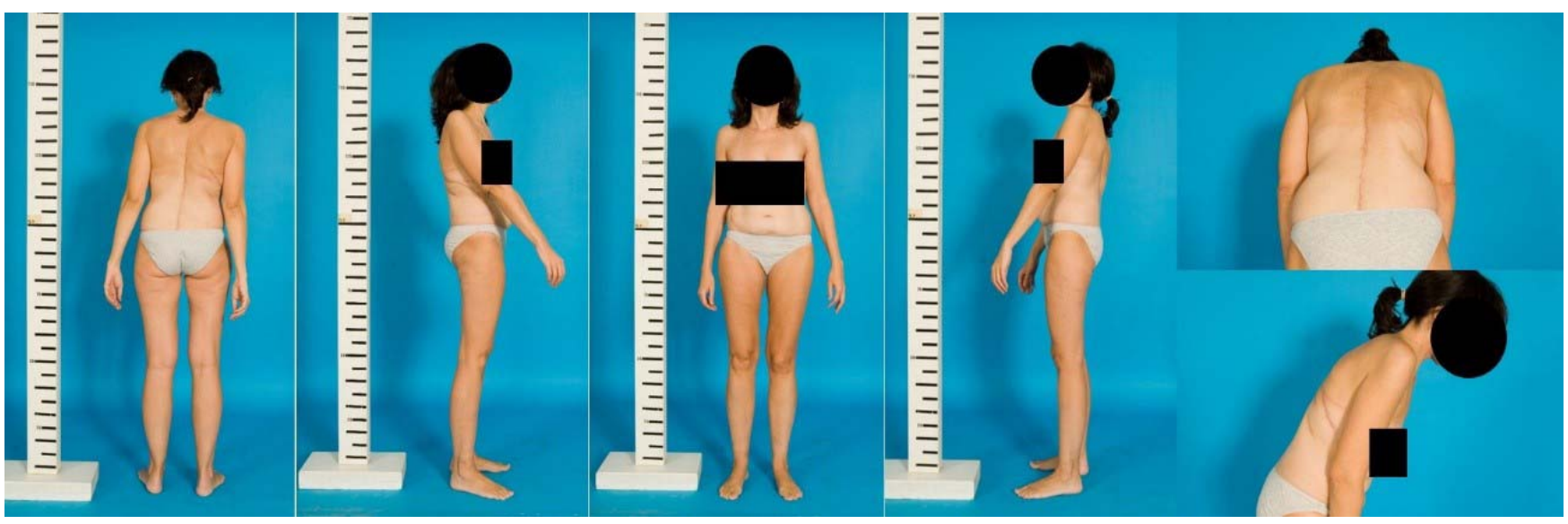

Figure 2. Final follow-up photographs of an adult idiopathic scoliosis patient (same patient as Figure 1).

multilevel fusion mass following a Harrington rod surgery, 1 patient had a history of a previous double approach for deformity surgery, and 2 patients had undergone prior lumbar fusion.

At first visit, before the photographs were taken, SRS-22 scores were as follows: activity $2.79 \pm 0.75$; self-image $2.71 \pm 0.82$; pain $2.53 \pm 1.10$; mental health $3.08 \pm 0.77$; satisfaction $3.46 \pm 1.20$; global $2.74 \pm 0.72$. At second visit, after showing patients their preoperative and final follow-up full-body photographs, SRS-22 scores were as follows: selfimage $2.9 \pm 0.75$; satisfaction $4.02 \pm 0.97$.

A statistically significant improvement was found in both self-image $(P=.000)$ and satisfaction $(P=$ .011) after showing patients their preoperative and final follow-up full-body photographs (Table 2). The null hypothesis was rejected.

\section{DISCUSSION}

Patient-reported outcome questionnaires have become the standard measure for treatment effectiveness after ASD surgery. ${ }^{10,11}$ The SRS-22 questionnaire has been validated in an adult deformity population $^{12,13}$ and is one the most widely used health-related quality-of-life instruments in adult deformity patients. ${ }^{6-8,14-18}$

Table 2. Comparison of Scoliosis Research Society Health-Related Quality of Life Questionnaire (SRS-22) satisfaction and self-image domains before and after showing patients their preoperative and final follow-up photographs.

\begin{tabular}{|c|c|c|c|c|c|}
\hline & \multicolumn{2}{|c|}{ Prephotography } & \multicolumn{2}{|c|}{ Postphotography } & \multirow[b]{2}{*}{$P$} \\
\hline & Mean \pm SD & $\begin{array}{l}\text { Min- } \\
\text { Max }\end{array}$ & Mean \pm SD & $\begin{array}{l}\text { Min- } \\
\text { Max }\end{array}$ & \\
\hline SRS-22 satisfaction & $3.46 \pm 1.20$ & $1-5$ & $4.02 \pm 0.97$ & $1-5$ & .011 \\
\hline SRS-22 self-image & $2.71 \pm 0.82$ & $1-4.6$ & $2.9 \pm 0.75$ & $2-5$ & .000 \\
\hline
\end{tabular}

Abbreviations: Min, minimum; Max, maximum.
Although it is unclear if patient satisfaction is associated with the extent of improvement in surgical outcome measures after spinal surgery, ${ }^{9}$ there is no doubt that the use of patient satisfaction metrics represents an important movement toward patient-centered care., ${ }^{2,3}$ However, determinants of patient satisfaction in ASD surgery have proven to be complex. ${ }^{19}$

We are unaware of any study that has previously examined if the use of clinical photography may have an influence in patient satisfaction after ASD surgery.

Only 2 prior studies ${ }^{4,5}$ have examined the effects of clinical photography in clinical results after spinal deformity surgery. In 2015, Albayarak et $\mathrm{al}^{4}$ compared the SRS-22 scores in 2 groups of 30 patients operated on for adolescent idiopathic scoliosis. Patients in group 1 were shown the preoperative and most recent follow-up photographs, while patients in group 2 were not shown their photographs. They found a statistically significant difference between the groups for question 10 (self-image), 18 (function), and 21 (satisfaction). No significant difference was found between the 2 groups in the SRS-22 domains. One year later, ${ }^{5}$ the same study group conducted a similar study in a population of 40 hyperkyphotic subjects with a mean age of 19 years. They proved that showing patients their preoperative and postoperative photographs improved postoperative patient satisfaction as measured by SRS-22R scores. This second study employed a different methodology using the same patients as the control group. We decided to adopt this approach for our study since we are under the impression that many confounding 


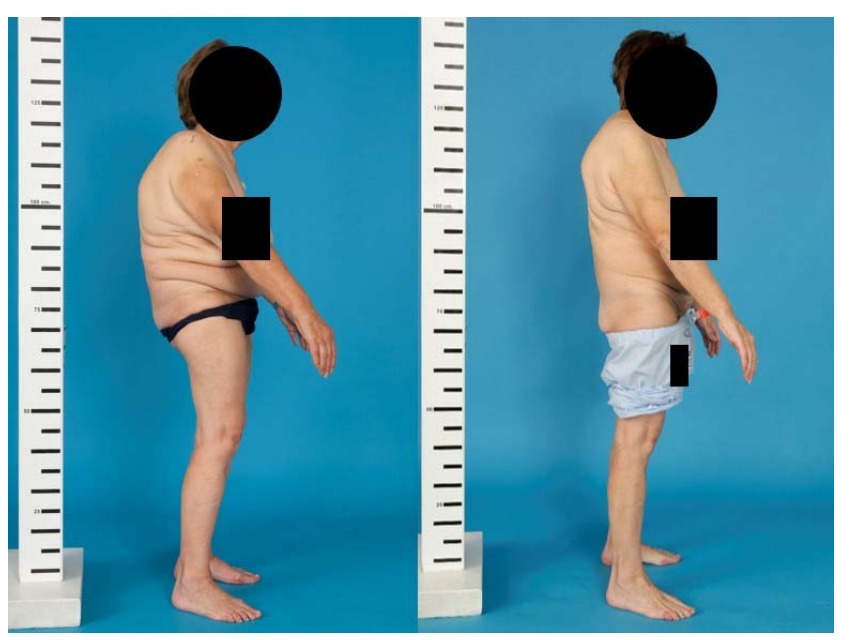

Figure 3. Preoperative and postoperative right-side upright position clinical photographs of a patient operated on for thoracolumbar kyphosis. Patient preoperative picture shows pelvic retroversion and knee flexion as compensatory mechanisms. Final follow-up photograph shows reversal of compensatory mechanisms.

factors can be avoided using the same patients as the control group. ${ }^{20}$

It should be noted that, contrary to our study, none of these 2 studies used a standardized identical photographic technique including the same equipment, lighting, and background. Another methodological difference that merits comment is that none of these 2 papers used full-body clinical photographs. ASD patients assume many different compensatory postures, including a retroverted pelvis, extended hips, flexed knees, and ankle dorsiflexion. ${ }^{21,22}$ Although in some patients a fullspine photograph may be sufficient to evaluate aesthetic changes after surgery, full-body photographs provide a better appreciation of the entire musculoskeletal system's participation in ASD compensation (Figure 3). Recent efforts to describe compensation in response to malalignment using the pelvis and lower limbs have demonstrated success using full-body stereoradiographic imaging (EOS imaging). ${ }^{22,23}$ Analogously, we used full-body photographs in our study since they allow clinicians and patients to better assess changes in compensatory mechanisms following surgery ${ }^{21}$ (Figure 3).

The main limitation of the present study is the small sample size; however, this is a limitation shared with the 2 previous studies evaluating the influence of clinical photography in patient satisfaction following spinal deformity surgery. ${ }^{4,5}$ Like the vast majority of studies on ASD surgery ${ }^{2,6-8,11,12,16-21}$ our study included patients with deformity caused by different etiological factors. Due to the heterogeneity in clinical settings, any potential change found in SRS-22 activity, pain, and mental health domains after showing patients their photographs could be difficult to interpret. For this reason, we decided to focus our study on patient satisfaction, bearing in mind that the SRS-22 self-image domain has a strong correlation with patient satisfaction following ASD surgery. ${ }^{2}$ Although our patients experienced improvement in the SRS self-image domain that barely reached a minimal clinically important difference calculated by standard error of measurement, ${ }^{17}$ a statistically significant improvement in SRS satisfaction was found. Unfortunately, the present study lacked longitudinal data that would allow us to be sure whether the improvement in patient satisfaction after seeing their photographs will be temporary or long lasting.

Despite these limitations, we provide the first evidence that patient satisfaction and self- image may improve after ASD surgery by the use of clinical photography. This could be an important starting point for introducing full-body clinical photographs as a routine clinical tool in adult deformity patients undergoing surgery.

\section{ACKNOWLEDGMENTS}

The authors wish to acknowledge Jose Dominguez Pallas, clinical photographer, for his involvement. This study was approved by the Institutional Research Ethics Committee.

\section{REFERENCES}

1. Tsai TC, Orav EJ, Jha AK. Patient satisfaction and quality of surgical care in US hospitals. Ann Surg. 2015;261(1):2-8.

2. Gum JL, Bridwell KH, Lenke LG, Bumpass DB, Sugrue PA, Karikari IO, Carreon LY. SRS22R appearance domain correlates most with patient satisfaction after adult deformity surgery to the sacrum at 5-year follow-up. Spine (Phila Pa 1976). 2015;40(16):1297-1302.

3. Truumees E. Appropriate use of satisfaction scores in spine care. Spine J. 2013;13(9):1013-1016.

4. Albayrak A, Buyuk AF, Ucpunar H, Balioglu MB, Kargin D, Kaygusuz MA. Pre- and postoperative photographs and surgical outcomes in patients with Lenke type 1 adolescent idiopathic scoliosis. Spine (Phila Pa 1976). 2015;40(7):469-474.

5. Albayrak A, Balioglu MB, Misir A, et al. Preoperative and postoperative photographs and surgical outcomes of patients with kyphosis. Spine (Phila Pa 1976). 2016;41(19):E1185-E1190.

6. Mannion AF, Elfering A, Bago J, et al. Factor analysis of 
the SRS-22 outcome assessment instrument in patients with adult spinal deformity. Eur Spine J. 2018;27(3):685-699.

7. Yoshida G, Boissiere L, Larrieu D, et al. Advantages and disadvantages of adult spinal deformity surgery and its impact on health-related quality of life. Spine (Phila Pa 1976). 2017;42(6):411-441.

8. Scheer JK, Mundis GM, Klineberg E, et al. Recovery following adult spinal deformity surgery: the effect of complications and reoperation in 149 patients with 2-year follow-up. Eur Spine J. 2016;25(8):2612-2621.

9. Bago J, Climent JM, Ey A, Perez-Grueso FJ, Izquierdo E. The Spanish version of the SRS-22 patient questionnaire for idiopathic scoliosis: transcultural adaptation and reliability analysis. Spine (Phila Pa 1976). 2004;29(15):1676-1680.

10. Godil SS, Parker SL, Zuckerman SL, et al. Determining the quality and effectiveness of surgical spine care: patient satisfaction is not a valid proxy. Spine J. 2013;13(9):1006-1012.

11. Glassman SD, Schwab F, Bridwell KH, Shaffrey C, Horton W, Hu S. Do 1-year outcomes predict 2-year outcomes for adult deformity surgery? Spine J. 2009;9(4):317-322.

12. Bridwell KH, Cats-Baril W, Harrast J, et al. The validity of the SRS-22 instrument in an adult spinal deformity population compared with the Oswestry and SF-12: a study of response distribution, concurrent validity, internal consistency, and reliability. Spine (Phila Pa 1976). 2005;30(4):455461.

13. Berven S, Deviren V, Demir-Deviren S, Hu SS, Bradford DS. Studies in the modified Scoliosis Research Society Outcomes Instrument in adults: validation, reliability, and discriminatory capacity. Spine (Phila Pa 1976). 2003;28(18):2164-2169.

14. Sánchez-Mariscal F, Gomez-Rice A, Rodríguez-López T, et al. Preoperative and postoperative sagittal plane analysis in adult idiopathic scoliosis in patients older than 40 years of age. Spine J. 2017;17(1):56-61.

15. Sánchez-Mariscal F, Gomez-Rice A, Izquierdo E, Pizones J, Zúñiga L, Alvarez-González P. Correlation of radiographic and functional measurements in patients who underwent primary scoliosis surgery in adult age. Spine (Phila Pa 1976). 2012;37(7):592-598.

16. Núñez-Pereira S, Vila-Casademunt A, Domingo-Sàbat $\mathbf{M}$, et al. Impact of early unanticipated revision surgery on health-related quality of life after adult spinal deformity surgery. Spine J. 2018;18(6):926-934.
17. Crawford CH III, Glassman SD, Bridwell KH, Berven $\mathrm{SH}$, Carreon LY. The minimum clinically important difference in SRS-22R total score, appearance, activity and pain domains after surgical treatment of adult spinal deformity. Spine (Phila Pa 1976). 2015;40(6):377-381.

18. Crawford CH III, Glassman SD, Bridwell KH, Carreon LY. The substantial clinical benefit threshold for SRS-22R domains after surgical treatment of adult spinal deformity. Spine Deform. 2016;4(5):373-377.

19. Hamilton DK, Kong C, Hiratzka J, et al. Patient satisfaction after adult spinal deformity surgery does not strongly correlate with health-related quality of life scores, radiographic parameters, or occurrence of complications. Spine (Phila Pa 1976). 2017;42(10):764-769.

20. Gliner JA, Morgan GA, Harmon RJ. Single-factor repeated-measures designs: analysis and interpretation. $J \mathrm{Am}$ Acad Child Adolesc Psychiatry. 2002;41(8):1014-1016.

21. Lamartina C, Berjano P. Classification of sagittal imbalance based on spinal alignment and compensatory mechanisms. Eur Spine J. 2014;23(6):1177-1189.

22. Jalai CM, Cruz DL, Diebo BG, et al. Full-body analysis of age-adjusted alignment in adult spinal deformity patients and lower-limb compensation. Spine (Phila Pa 1976). 2017;42(9):653-661.

23. Jalai CM, Diebo BG, Cruz DL, et al. The impact of obesity on compensatory mechanisms in response to progressive sagittal malalignment. Spine J. 2017;17(5):681-688.

Disclosures and COI: The authors state no conflict interest in relation to this study.

Corresponding Author: Alejandro GomezRice, Hospital Ramon y Cajal, M-607, km. 9.100, 28034, Madrid, Spain. Phone: (+34913368000); Email: alexgomezrice@hotmail.com.

Published 22 January 2021

This manuscript is generously published free of charge by ISASS, the International Society for the Advancement of Spine Surgery. Copyright (c) 2020 ISASS. To see more or order reprints or permissions, see http://ijssurgery.com. 